\title{
HUBUNGAN KONSUMSI MAKANAN KARIOGENIK DAN PERAN ORANG TUA DALAM KEBIASAAN MENGGOSOK GIGI DENGAN KEJADIAN KARIES GIGI PADA ANAK SINDROM DOWN DI SEKOLAH LUAR BIASA (SLB) DHARMA BAKTI DHARMA PERTIWI BANDAR LAMPUNG
}

\author{
Ika Artini ${ }^{1}$, Mutia Permatasari ${ }^{2}$ \\ ${ }^{1}$ Departemen Farmakologi, Fakultas Kedokteran, Universitas Malahayati \\ ${ }^{2}$ Program Studi Kedokteran, Fakultas Kedokteran, Universitas Malahayati
}

\begin{abstract}
The Relationship of Kariogenic Food Consumption and the Role of Parents in Tooth Brushing Habits with the Occurrence of Dental Caries in Children with Down Syndrome in Extraordinary Schools Dharma Bakti Dharma Pertiwi Bandar Lampung. Caries is one of teeth infection that destructing teeth structures and cause problems cavities. While cariogenic food is identified as caries trigger. The characteristic of cariogenic food are classified such as much carbohydrate substance, sticky and crumble. Additionaly, the other factors of caries created is unprecedural brushing teeth habituality. In children with down syndrome have oral abnormalities, one of them dental caries. This research has aim to understand the relationship between the consumption of cariogenic food and the role of parents in the habit of brushing teeth with the incidence of dental caries in children with down syndrome at special school of Dharma Bakti Dharma Pertiwi of Bandar Lampung year 2017. This study used an analytical survey with cross sectional approach with 40 respondets on down syndrome children at special elementary school. Statistical study was done through Chi Square test. The results of this research show that almost of students experiencecaries, consuming cariogenic food indicated in not good and the role of parents in the habit of brusing teeth indicated in not good enough. The variable of consuming cariogenic food imply close relations with caries issues ( $p$ values $=0.004$ ) and whereas brushing teeth habituality also imply close relations with caries issues ( $p$ value $=0.000$ ). it can be concluded that consuming cariogenic foods and the role of parents in the habit of brushing teeth imply close relations with caries issues at special school Dharma Bakti Dharma Pertiwi of Bandar Lampung Year 2017.
\end{abstract}

Keywords: Cariogenic Food, Brushing Teeth, Down Syndrome, Caries

\begin{abstract}
Abstrak: Hubungan Konsumsi Makanan Kariogenik Dan Peran Orang Tua Dalam Kebiasaan Menggosok Gigi dengan Kejadian Karies Gigi Pada Anak Sindrom Down Di Sekolah Luar Biasa (SIb) Dharma Bakti Dharma Pertiwi Bandar Lampung Tahun 2017. Karies gigi adalah sebuah penyakit infeksi yang merusak struktur gigi dan menyebabkan gigi berlubang. Makanan kariogenik adalah makanan yang menyebabkan karies gigi. Sifat makanan kariogenik adalah banyak mengandung karbohidrat, lengket dan mudah hancur didalam mulut. Faktor yang dapat menyebabkan karies gigi diantaranya kebiasaan menggosok gigi yang tidak sesuai prosedur. Pada anak sindrom down mempunyai kelainan oral salah satunya karies gigi. Penelitian ini bertujuan untuk mengetahui hubungan konsumsi makanan kariogenik dan peran orang tua dalam kebiasaaan menggosok gigi dengan kejadian karies gigi pada anak sindrom down di Sekolah Luar Biasa (SLB) Dharma Bakti Dharma Pertiwi Bandar Lampung Tahun 2017. Penelitian ini merupakan survei analitik dengan desain cross sectional, dengan jumlah sampel sebanyak 40 responden di SDLB pada anak sindrom down. Uji statistik menggunakan uji Chi Square didapatkan hasil sebagian besar siswa terkena karies gigi, konsumsi makanan kariogenik termasuk kategori tidak baik dan juga peran orang tua dalam kebiasaan menggosok gigi termasuk kategori tidak baik. Variabel konsumsi makanan kariogenik mempunyai hubungan bermakna dengan kejadian karies gigi
\end{abstract}


( $\mathrm{p}$ value $=0.004$ ) dan peran orang tua dalam kebiasaan menggosok gigi mempunyai hubungan bermakna dengan kejadian karies gigi ( $p$ value $=0,000$ ). Dapat disimpulkan bahwa konsumsi makanan kariogenik dan peran orang tua dalam kebiasaan menggosok gigi berhubungan dengan kejadian karies gigi di SLB Dharma Bakti Dharma Pertiwi Bandar Lampung Tahun 2017.

\section{Kata kunci: Makanan Kariogenik, Menggosok Gigi, Karies Gigi, Sindrom Down}

\section{PENDAHULUAN}

Makanan

yang sering

dikonsumsi anak sekolah dasar (SD)

banyak bersifat kariogenik, seperti makanan manis, lengket dan makanan yang berbentuk menarik. Efek buruk dari seringnya mengkonsumsi makanan manis atau kariogenik yaitu terhadap kesehatan gigi. Hal ini disebabkan karena makanan kariogenik mempunyai kecenderungan melekat pada permukaan gigi. Bila hal ini sering terjadi maka dapat menyebabkan karies gigi. (Sumini, Amikasari, Nurhayati, 2014).

Karies adalah permasalahan gigi dan mulut yang sering terjadi di masyarakat. Karies gigi adalah penyakit jaringan gigi yang ditandai dengan kerusakan jaringan dimulai dari permukaan gigi (ceruk, fisura dan daerah interproksimal) meluas ke arah pulpa. Karies gigi dapat dialami setiap orang dan dapat timbul pada satu permukaan gigi atau lebih serta dapat meluas ke bagian yang lebih dalam dari gigi, misalnya dari email ke dentin atau ke pulpa (Tarigan, 2013). Karies gigi merupakan kesehatan gigi yang dapat dicegah. Pencegahan karies gigi dapat menurunkan angka kejadian karies gigi. Salah satu pencegahan karies yang dapat dilakukan adalah menggosok gigi dengan pola (waktu, frekuensi dan teknik) menggosok gigi yang tepat. Waktu menyikat gigi yang baik adalah setelah makan dan sebelum tidur. (Gopdianto; Rattu; Mariati, 2014).

\section{American Dental Association}

(ADA) menyatakan bahwa pasien harus menyikat gigi secara teratur, minimal 2 kali sehari yaitu pagi setelah sarapan dan sebelum tidur malam. Teknik menyikat gigi yang dapat dilakukan adalah dengan teknik maju mundur, horizontal, memutar dan lainya seperti teknik dengan metode Roll, metode Bass, metode Charter, metode Fones dan metode Stillman. Karies gigi dapat terjadi pada semua anak, namun anak-anak berkebutuhan khusus lebih sering mengalaminya. Hal ini disebabkan adanya keterbatasan kemampuan kognitif dan mobilitas, gangguan perilaku dan otot, refleks muntah dan gerakan tubuh tidak terkontrol. Keadaan inilah yang membatasi anak-anak tersebut untuk dapat melakukan pembersihan gigi yang optimal dan menempatkan mereka pada posisi berisiko mengalami masalah kesehatan gigi dan mulut. (Sumini, Amikasari, Nurhayati 2014).

Anak usia 6-12 tahun mempunyai gigi campuran antara gigi sulung dan gigi permanen, untuk itu kesehatan gigi anak perlu dijaga sejak awal agar anak memiliki gigi permanen yang baik sehingga gigi permanen dapat berfungsi sebagaimana mestinya sejak anak-anak sampai seterusnya (WHO,2013). Menurut World Health Organization (WHO) diseluruh dunia $60-90 \%$ dari anak-anak sekolah dan hampir $100 \%$ orang dewasa mengalami karies gigi, yang sering menimbulkan rasa sakit dan ketidak nyamanan. Prevalensi akan terus meningkat seiring bertambahnya usia. Anak usia 6 (enam) tahun yang telah mengalami karies pada gigi tetapnya adalah $20 \%$ meningkat $60 \%$ pada usia 8 (delapan) tahun, $85 \%$ pada 10 (sepuluh) tahun dan $90 \%$ pada usia 12 (dua belas) tahun.

Data Riset Kesehatan Dasar (RISKESDAS) menunjukan peningkatan prevalensi terjadinya karies aktif pada penduduk Indonesia dibandingkan tahun 2007 lalu, yaitu dari 43,4\% (2007) menjadi 53,3\% (2013). Berdasarkan provinsi bahwa 
hampir semua provinsi mengalami kenaikan prevalensi karies aktif dari tahun 2007 ke tahun 2013, hanya 4 provinsi yang mengalami penurunan, yaitu: Maluku Utara, Papua Barat, Jogjakarta dan Riau. Peningkatan tertinggi terdapat pada provinsi Sulawesi Selatan $(29,1 \%)$ dan Lampung $(23,6 \%)$, yaitu 2 kali lebih peningkatan Nasional (9,8\%) (RISKESDAS, 2013).

Berdasarkan Profil Kesehatan Propinsi Lampung tahun 2013, masalah mengenai gigi mulut yang paling tinggi yaitu kasus karies gigi, terlihat dari jumlah kasus tumpatan gigi mencapai 13.287 kasus dan pencabutan gigi mencapai 69.391 kasus (Dinas Kesehatan Provinsi Lampung, 2013). Sedangkan data kejadian karies gigi di Bandar Lampung yang didapatkan dari data laporan bulanan khususnya pada usia 10-14 tahun didapatkan data jumlah penderita karies baru sebanyak 533 orang dengan jumlah penderita lama 198 orang.

Kelebihan konsumsi gula cenderung dapat mengakibatkan terjadinya karies gigi. American Heart Association (AHA) menemukan konsumsi gula yang tinggi terjadi pada anak, yaitu anak usia 1-3 tahun mengkonsumsi gula 12 sendok teh per hari dan anak usia 4-8 tahun mengkonsumsi gula 21 sendok teh perhari (Devi, 2012). Data RISKESDAS bahwa $53,1 \%$ penduduk Indonesia mengkonsumsi makanan manis (RISKESDAS, 2013). Sebaiknya dalam sehari kebiasaan mengemil dibatasi 4kali/hari untuk total makanan kariogenik dan $3 \mathrm{kali} /$ minggu agar gigi mempunyai waktu untuk menetralisir asam yang ada dalam mulut (Ramadhan, 2010).

Perilaku menggosok gigi pada masyarakat Indonesia, terjadi peningkatan proporsi penduduk yang menggosok giginya setiap hari dari tahun 2007 sebesar 91,1\% menjadi $93,8 \%$ tahun 2013. Akan tetapi cara menggosok gigi dengan benar (menggosok gigi dua kali dalam sehari pada saat sesudah makan pagi dan sebelum tidur malam) memiliki angka yang sangat kecil pada tahun 2007 yaitu $7,3 \%$ angkat tersebut pun juga mengalami penurunan pada tahun 2013 menjadi 2,3\% (RISKESDAS, 2013). Bedasarkan Data RISKESDAS tahun 2007 untuk 10 tahun ke atas yang menggosok gigi setiap hari dan menggosok gigi dengan benar masih sangat rendah yaitu $7,3 \%$. Sedangkan yang terendah di Provinsi Lampung $(2,1 \%)$, Sumatera Barat $(2,7 \%)$ dan Jambi $(3,7 \%)$ (RISKESDAS, 2013).

Berdasarkan data Pusat

kesehatan masyarakat (Puskesmas) Beringin Raya dari hasil penjaringan Sekolah Dasar untuk gigi dan mulut tahun 2016 menyatakan bahwa anak Sekolah Dasar Luar Biasa yang mengalami karies gigi paling tinggi yaitu mencapai kurang lebih $50-70 \%$ siswa dibandingkan anak Sekolah Dasar normal yaitu hanya mencapai kurang lebih $30-40 \%$ siswa.

Berdasarkan wawancara prilaku menggosok gigi yang dilakukan oleh peneliti pada wali siswa sekolah dasar anak sindrom down di Sekolah Luar Biasa (SLB) Dharma Bakti Dharma Pertiwi Bandar Lampung didapatkan bahwa 20\% siswa dapat menggosok gigi sendiri karena sudah terbiasa dan terlatih sedangkan $80 \%$ siswa menggosok gigi dengan cara dibantu karena belum terlatih dan terbiasa.

Berdasarkan hal diatas maka penulis tertarik untuk mengadakan penelitian mengenai "Hubungan Konsumsi Makanan Kariogenik dan Kebiasaan Menggosok Gigi dengan Kejadian karies Gigi pada Anak Sindrom Down di Sekolah Luar Biasa (SLB) Dharma Bakti Dharma Pertiwi Bandar Lampung Tahun 2017".

\section{METODE PENELITIAN}

Penelitian ini menggunakan metode survey analitik, dengan pendekatan cross sectional. Penelitian ini dilaksanakan pada bulan April 2017. Teknik Sampling yang di gunakan yaitu total sampling pengumpulan data secara data primer meliputi konsumsi makanan kariogenik dan peran orang tua dalam kebiasaan 
menggosok gigi dengan menggunakan diperoleh dari pemeriksaan langsung dengan sonde, kaca mulut. Data sekunder adalah data jumlah siswa siswi anak sindrom down di SLB Dharma Bhakti Dharma Pertiwi Bandar Lampung Tahun 2017 yang diperoleh dari Kepala Sekolah.

HASIL

Gambaran Umum Responden dan Lokasi Penelitian

Penelitian ini dilakukan pada tanggal 11 April 2017 di Sekolah Luar Biasa (SLB) Dharma Bakti Dharma Pertiwi Bandar Lampung ini merupakan sekolah yang memiliki siswa/siswi anak sindrom down yang memiliki kelainan pada gigi. Hal ini menjadikan prevalensi gigi karies pada anak sindrom down di SLB Dharma Bakti Dharma Pertiwi Bandar Lampung juga tinggi mencapai kurang lebih 50 $70 \%$ menurut data penjaringan Puskesmas Beringin Raya tahun 2016. Analisis data dalam penelitian ini menggunakan data 40 responden, dimana dari 76 siswa/siswi sebagai populasi hanya terdapat 40 siswa/siswi yang memenuhi kriteria sampel dalam penelitian ini. Anak sekolah dasar sindrom down laki-laki dan perempuan. Data yang diperoleh tersebut kemudian di analisa dengan menggunakan analisis univariat dan bivariat.

\section{Hasil Univariat}

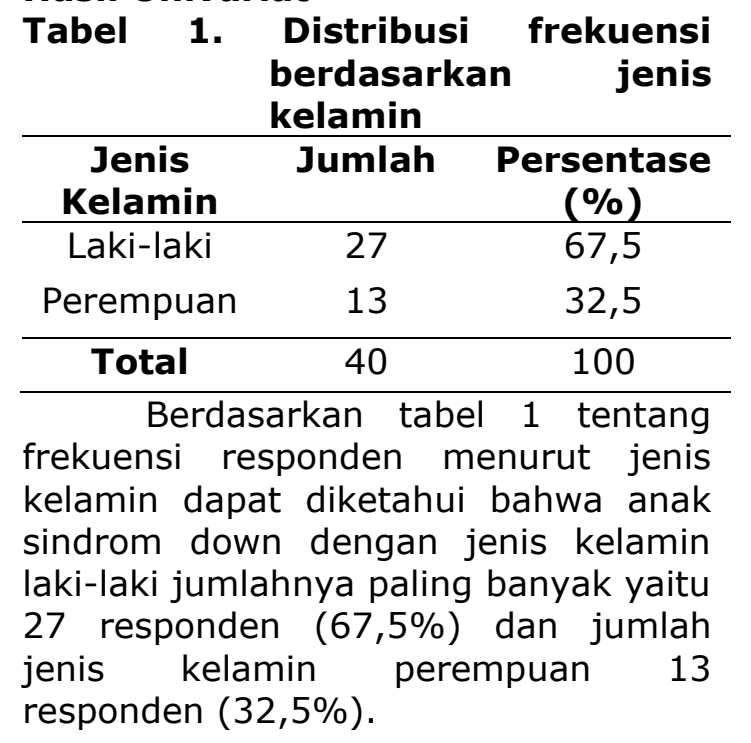

lembar kuesioner. Data karies gigi

Tabel 2. Distribusi frekuensi berdasarkan karies gigi

\begin{tabular}{ccc}
\hline Karies Gigi & Jumlah & $\begin{array}{c}\text { Persentase } \\
(\%)\end{array}$ \\
\hline Tidak karies & 8 & 20 \\
Karies & 32 & 80 \\
\hline
\end{tabular}

Total $\quad 40 \quad 100$

Dari tabel 2 Distribusi frekuensi berdasarkan karies gigi pada anak sindrom down di SLB Dharma Bakti Dharma Pertiwi Bandar Lampung sebanyak 40 responden di yang memiliki karies gigi yaitu sebanyak 32 siswa $(80 \%)$ dan yang tidak karies gigi yaitu sebanyak 8 siswa (20\%).

\begin{tabular}{ccc} 
Tabel 3. & $\begin{array}{c}\text { Distribusi } \\
\text { berdasarkan } \\
\text { supernumerary }\end{array}$ & frekuensi \\
\hline $\begin{array}{c}\text { Super- } \\
\text { numerary }\end{array}$ & Jumlah & $\begin{array}{c}\text { Persentase } \\
(\%)\end{array}$ \\
\hline $\begin{array}{c}\text { Tidak } \\
\text { Ya }\end{array}$ & 35 & 87,5 \\
12,5 \\
\hline Total & 5 & $\mathbf{1 0 0}$
\end{tabular}

Dari tabel 3 Distribusi frekuensi berdasarkan supernumerary pada anak sindrom down di SLB Dharma Bakti Dharma Pertiwi Bandar Lampung sebanyak 40 responden di dapatkan yang tidak yaitu sebanyak 35 siswa $(87,5 \%)$ dan yang ya yaitu sebanyak 5 siswa $(12,5 \%)$.

\begin{tabular}{ccc} 
Tabel 4. & $\begin{array}{c}\text { Distribusi } \\
\text { berdasarkan } \\
\text { maloklusi }\end{array}$ & frekuensi \\
\hline Maloklusi & $\begin{array}{c}\text { Jumlah } \\
\text { Persentase } \\
(\%)\end{array}$ \\
\hline Tidak & 40 & 100 \\
Ya & 0 & 0 \\
\hline Total & $\mathbf{4 0}$ & $\mathbf{1 0 0}$ \\
\hline
\end{tabular}

Dari tabel 4 Distribusi frekuensi berdasarkan maloklusi pada anak sindrom down di SLB Dharma Bakti Dharma Pertiwi Bandar Lampung sebanyak 40 responden di dapatkan yang tidak yaitu sebanyak 40 siswa $(100 \%)$. 
Tabel

5. Distribusi frekuensi berdasarkan konsumsi makanan kariogenik

\begin{tabular}{ccc}
\hline $\begin{array}{c}\text { Konsumsi } \\
\text { makanan } \\
\text { kariogenik }\end{array}$ & Jumlah & $\begin{array}{c}\text { Persentase } \\
(\%)\end{array}$ \\
\hline Baik & 17 & 42,5 \\
Tidak Baik & 23 & 57,5 \\
\hline Total & $\mathbf{4 0}$ & $\mathbf{1 0 0}$ \\
\hline
\end{tabular}

Berdasarkan tabel 5 pada anak sindrom down dari total 40 responden di dapatkan hasil konsumsi makanan kariogenik yang tidak baik yaitu sebanyak 23 siswa $(57,5 \%)$ dan baik sebanyak 17 siswa $(42,5 \%)$.

\begin{tabular}{ccc} 
Tabel 6. & $\begin{array}{l}\text { Distribusi } \\
\text { berdasarkan } \\
\text { orang tua } \\
\text { kebiasaan menggosok } \\
\text { gigi }\end{array}$ & $\begin{array}{c}\text { frekensi } \\
\text { dalam }\end{array}$ \\
\hline $\begin{array}{c}\text { Peran } \\
\text { orang tua }\end{array}$ & Jumlah & $\begin{array}{c}\text { Persentase } \\
(\%)\end{array}$ \\
\hline Baik & 13 & 32,5 \\
Tidak Baik & 27 & 67,5 \\
\hline Total & $\mathbf{4 0}$ & $\mathbf{1 0 0}$ \\
\hline
\end{tabular}

Berdasarkan tabel 6 pada anak sindrom down dari total 40 responden di dapatkan hasil peran orang tua dalam kebiasaan menggosok gigi yang tidak baik yaitu sebanyak 27 siswa $(67,5 \%)$ dan baik sebanyak 13 siswa $(32,5 \%)$.
Berdasarkan tabel 7 dari 17 responden dengan konsumsi makanan kariogenik yang baik di dapatkanresponden dengan karies gigi sebanyak 10 siswa $(25,0 \%)$ danresponden dengan tidak karies gigi sebanyak 7 siswa $(17,5 \%)$. Sedangkan dari 23 responden dengan konsumsi makanan kariogenik yang tidak baik di dapatkan responden dengankaries gigi sebanyak 22 siswa $(55,9 \%)$ dan responden dengan tidak karies gigi sebanyak 1 siswa $(2,5 \%)$.

\section{Hasil Uji Analisis Bivariat dengan Uji Chi-square \\ Analisis bivariat dilakukan} untuk mendapatkan hasil tabulasi silang antara variabel bebas (konsumsi makanan kariogenik dan peran orang tua dalam kebiasaan menggosok gigi) dengan variabel terkait (karies gigi) di SLB Dharma Bakti Dharma Pertiwi Bandar Lampung serta untuk mengetahui $p$ value dari hasil uji hipotesis yang telah dilakukan peneliti

Berdasarkan hasil tabel 7 dengan uji statistik chi-square diperoleh nilai $p=0,004(p<0,05) \mathrm{O}=$ 15,400 (95\% CI: 1,665-142,451). Responden dengan konsumsi makanan kariogenik yang tidak baik lebih beresiko 15,4 kali lipat mengalami karies dari pada responden yang konsumsi makanan kariogenik yang baik.

Tabel 7. Hubungan Konsumsi Makanan Kariogenik dengan Kejadian Karies Gigi pada Anak Sindrom Down di SLB Dharma Bakti Dharma Pertiwi Bandar Lampung

\begin{tabular}{|c|c|c|c|c|c|c|c|c|}
\hline \multirow{2}{*}{$\begin{array}{c}\text { Konsumsi } \\
\text { makanan } \\
\text { kariogenik }\end{array}$} & \multicolumn{2}{|c|}{$\begin{array}{c}\text { Tidak } \\
\text { Karies } \\
\end{array}$} & \multicolumn{2}{|c|}{ Karies } & \multicolumn{2}{|c|}{ Total } & \multirow[t]{2}{*}{ p-value } & \multirow[t]{2}{*}{$\begin{array}{c}\text { OR } \\
95 \% \text { CI }\end{array}$} \\
\hline & $F$ & $\%$ & $\mathrm{~F}$ & $\%$ & $\mathrm{~F}$ & $\%$ & & \\
\hline Baik & 7 & 17,5 & 10 & 25,0 & 17 & 42,5 & \multirow{3}{*}{.004} & \multirow{3}{*}{$\begin{array}{c}15,400 \\
(1,665- \\
142,451\end{array}$} \\
\hline Tidak Baik & 1 & 2,5 & 22 & 55,0 & 23 & 57,5 & & \\
\hline Jumlah & 8 & 20,0 & 32 & 80,0 & 40 & 100 & & \\
\hline
\end{tabular}


Sekurang-kurang nya lebih beresiko sebesar 1,665 kali lipat dapat mengalami karies gigi dan paling beresiko sebesar 142,451 kali lipat dapat mengalami karies gigi. Sehingga $\mathrm{Ha}$ diterima yang berarti terdapat hubungan yang signifikan antara konsumsi makanan kariogenik dengan kejadian karies gigi padaanak sindrom down di SLB Dharma Bakti Dharma Pertiwi Bandar Lampung.

Tabel 8. Hubungan Peran Orang Tua dalam Kebiasaan Menggosok Gigi dengan Kejadian Karies Gigi pada Anak Sindrom down di SLB Dharma Bakti Dharma Pertiwi Bandar Lampung

\begin{tabular}{ccccccccc}
\hline $\begin{array}{c}\text { Peran } \\
\text { Orangtua }\end{array}$ & \multicolumn{2}{c}{$\begin{array}{c}\text { Tidak } \\
\text { Karies }\end{array}$} & Karies & Total & p-value & $\begin{array}{c}\text { OR } \\
\mathbf{9 5 \%} \text { CI }\end{array}$ \\
\cline { 2 - 9 } & $\mathrm{F}$ & $\%$ & $\mathrm{~F}$ & $\%$ & $\mathrm{~F}$ & $\%$ & & \\
\hline Baik & 7 & 17,5 & 6 & 15,0 & 13 & 32,5 & & 30,333 \\
Tidak Baik & 1 & 2,5 & 26 & 65,0 & 27 & 67,5 & .000 & $\begin{array}{c}(3,116- \\
295,249)\end{array}$ \\
Jumlah & 8 & 20,0 & 32 & 80,0 & 40 & 100 & & \\
\hline
\end{tabular}

Berdasarkan tabel 8 di atas dari 13 responden dengan peran orang tua dalam kebiasaan menggosok gigi yang baik di dapatkan responden dengan tidak karies gigi sebanyak 7 siswa $(17,5 \%)$ dan responden dengan karies sebanyak 6 siswa $(15,0 \%)$. Sedangkan dari 27 responden dengan peran orang $=0,000(p<0,05)$ OR $=30,333(95 \%$ CI: 3,116-295,249). Responden dengan peran orang tua dalam kebiasaan menggosok gigi yang tidak baik lebih beresiko 30,3 kali lipat mengalami karies dari pada responden yang peran orang tua dalam kebiasaan menggosok gigi yang baik. Sekurangkurang nya lebih beresiko sebesar 3,116 kali lipat dapat mengalami karies gigi dan paling beresiko sebesar 295,249 kali lipat dapat mengalami karies gigi.Sehingga Ha diterima yang berarti terdapat hubungan yang signifikan antara peran orang tua dalam kebiasaan menggosok gigidengan kejadian karies gigi padaanak sindrom down di SLB Dharma Bakti Dharma Pertiwi Bandar Lampung.

\section{PEMBahasan}

Berdasarkan tabel 7 di atas dari 17 responden dengan konsumsi tua dalam kebiasaan menggosok gigi yang tidak baikdi dapatkan responden dengankaries gigi sebanyak 26 siswa $(65,0 \%)$ dan responden dengan tidak karies gigi sebanyak 1 siswa (2,5\%).

Berdasarkan hasil tabel 8 dengan uji statistik chi-square diperoleh nilai $p$ makanan kariogenik yang baik di dapatkan responden dengan karies gigi sebanyak 10 siswa $(25,0 \%)$ dan responden dengan tidak karies gigi sebanyak 7 siswa $(17,5 \%)$. Sedangkan dari 23 responden dengan konsumsi makanan kariogenik yang tidak baik di dapatkan responden dengan karies gigi sebanyak 22 siswa $(55,9 \%)$ dan responden dengan tidak karies gigi sebanyak 1 siswa (2,5\%).

Di dalam penelitian ini didapat 10 responden yang mengalami karies meskipun konsumsi makanan kariogenik nya baik hal ini mungkin disebabkan karena menggosok gigi dan kebersihan mulutnya yang kurang baik dan didapat 1 responden yang tidak mengalami karies gigi meskipun konsumsi makanan kariogeniknya tidak baik hal ini mungkin disebabkan karena menggosok gigi dan kebersihan mulutnya baik. Berdasarkan hasil penelitian di atas dapat diketahui 
bahwa $p$ value $0.004<0,05$ yang berarti ada hubungan konsumsi makanan kariogenik dengan kejadian karies gigi. Hasil ini sejalan dengan penelitian Hana Yuan tahun 2013 tentang hubungan konsumsi makanan kariogenik dengan kejadian karies gigi dan status gizi pada anak kelas III dan IV SDN Kadipaten I dan II Kabupaten Bojonegoro. Hasil penelitian di dapat ada hubungan konsumsi makanan kariogenik dengan karies gigi ( $p$ value $=0,009)$.

Tingkat konsumsi makanan kariogenik ini dilihat dari frekuensi makan makanan manis. Frekuensi makanan yang mengandung sukrosa yang terdapat pada makanan manis dan cemilan (snack) merupakan faktor yang paling penting dalam hubungan diet dengan kesehatan gigi.Bila makanan kariogenik meningkat, maka indeks karies giginya semakin tinggi. Makanan yang bersifat manis bila dikonsumsi lebih dari 5 menit di dalam mulut akan lebih beresiko menyebabkan karies karena semakin lama makanan di biarkan akan menimbulkan plak yang menyebabkan gigi berlubang.

Menurut peneliti ada hubungan konsumsi makanan kariogenik dengan kejadian karies gigi pada anak sindrom down di SLB Dharma Bakti Dharma Pertiwi Bandar Lampung disebabkan karena Anak dan makanan manis merupakan dua hal yang sulit untuk dipisahkan. Anak memiliki kegemaran mengkonsumsi jenis jajanan secara berlebihan seperti permen, coklat, donat, kue isi selai, gulali, makanan ringan (snack) dan lain nya. Makanan tersebut bersifat manis dan menarik, sehingga anak menyukai makanan tersebut. Makanan yang menempel pada permukaan gigi jika dibiarkan akan terjadi beberapa bakteri penyebab karies di rongga mulut akan mulai memproduksi asam yang menyebabkan terjadi demineralisasi yang berlangsung selama 20-30 menit setelah makan. Di antara periode makan, saliva akan bekerja menetralisasi asam dan membantu proses remineralisasi. Namun apabila makanan terlalu sering dikonsumsi, maka enamel gigi tidak akan mempunyai kesempatan untuk melakukan remineralisasi dengan sempurna sehingga terjadinya karies

Berdasarkan tabel 8 di atas dari 13 responden dengan peran orang tua dalam kebiasaan menggosok gigi yang baik di dapatkan responden dengan tidak karies gigi sebanyak 7 siswa $(17,5 \%)$ dan responden dengan karies sebanyak 6 siswa (15,0\%). Sedangkan dari 27 responden dengan peran orang tua dalam kebiasaan menggosok gigi yang tidak baik di dapatkan responden dengan karies gigi sebanyak 26 siswa $(65,0 \%)$ dan responden dengan tidak karies gigi sebanyak 1 siswa (2,5\%).

Di dalam penelitian ini didapat 6 responden yang mengalami karies meskipun peran orang tua dalam kebiasaan menggosok gigi nya baik hal ini mungkin disebabkan karena responden mengkonsumsi makanan kariogenik yang berat dan terlalu sering dan didapat 1 responden yang tidak mengalami karies gigi meskipun peran orang tua dalam kebiasaan menggosok gigi nya tidak baik hal ini mungkin disebabkan karena responden mengkonsumsi makanan kariogenik yang ringan dan jarang. Berdasarkan hasil penelitian di atas dapat diketahui bahwa $p$ value $=0.000<0,05$ yang berarti ada hubungan peran orang tua dalam kebiasaan menggosok gigi dengan kejadian karies gigi. Hasil ini sejalan dengan penelitian Fitria Diumayanti tahun 2012 tentang Hubungan Antara Kebiasaan Menggosok Gigi Dengan Kejadian Karies Gigi Pada Siswa SD Negeri 04 Pasa Gadang Di Wilayah Kerja Puskesmas Pemancungan Padang Selatan Tahun 2011. Hasil penelitian di dapat ada hubungan antara kebiasaan menggosok gigi dengan kejadian karies gigi ( $p$ value $=0,010$ ).

Tetapi tidak sejalan dengan penelitian Siti Alimah tentang hubungan kebiasaan menggosok gigi dengan timbulnya karies gigi pada anak usia sekolah kelas 4-6 di SDN Ciputat 6 Tangerang Selatan Provinsi Banten Tahun 2013. Hasil penelitian di 
dapat tidak ada hubungan antara kebiasaan menggosok gigi dengan karies gigi ( $p$ value $=0,346$ ).

Kebiasaan menggosok gigi merupakan tindakan pemeliharaan atau menjaga rongga mulut agar tetap bersih dan sehat untuk mencegah terjadinya karies, serta bau mulut.Tujuan pemeliharaan oral higine adalah untuk menyingkirkan atau mencegah timbulnya plak gigi dan sisa-sisa makanan yang melekat di gigi.Kebiasaan menggosok gigi dalam kesehatan gigi dan mulut sangat penting, beberapa penyakit gigi dan mulut bisa terjadi karena kita kurang menjaga kebersihan gigi dan mulut seperti karies gigi. Kebiasaan makan anak-anak sekolah dasar yang sering dijumpai pada umumnya suka jajan makanan manis seperti cokelat, permen, es krim, biskuit, dan lain-lain. Sebenarnya hal tersebut tidak akan jadi masalah bila sesudah mengonsumsi makanan yang mengandung gula hendaknya gigi segera dibersihkan paling tidak dengan berkumur-kumur.

Menurut peneliti ada hubungan peran orang tua dalam kebiasaan menggosok gigi dengan kejadian karies gigi karena kurangnya pengetahuan anak mengenai menggosok gigi yang benar dan kurangnya menjaga kebersihan mulut dibanding orang dewasa yang dapat mempengaruhi mereka dalam menjaga kebersihan mulut.Sedangkan pola makan yang dapat menyebabkan timbulnya plak pada gigi yaitu makanan yang mengandung gula (kariogenik) yang melekat dipermukaan gigi. Pola makanan yang mengandung konsentrasi gula melebihi batas minimum, akan menghasilkan banyak asam sehingga terjadi karies gigi.

\section{KESIMPULAN}

Berdasarkan hasil penelitian tentang Hubungan Konsumsi Makanan Kariogenik dan Peran Orang Tua dalam Kebiasaan Menggosok Gigi dengan Kejadian Karies Gigi pada Anak Sindrom Down di Sekolah Luar Biasa
(SLB) Dharma Bakti Dharma Pertiwi Bandar Lampung Tahun 2017 maka dapat di simpulkan sebagai berikut:

1. Distribusi frekuensi karies gigi pada anak sindrom down di SLB Dharma Bakti Dharma Pertiwi Bandar Lampung adalah kategori karies sebanyak 32 siswa $(80 \%)$, sedangkan kategori tidak karies sebanyak 8 siswa (20\%).

2. Distribusi frekuensi konsumsi makanan kariogenik pada anak sindrom down di SLB Dharma Bakti Dharma Pertiwi Bandar Lampung adalah kategori tidak baik sebanyak 23 siswa (57,5\%), sedangkan kategori baik sebanyak 17 siswa $(42,5 \%)$.

3. Distribusi frekuensi peran orang tua dalam kebiasaan menggosok gigi pada anak sindrom down di SLB Dharma Bakti Dharma Pertiwi Bandar Lampung adalah kategori tidak baik yaitu sebanyak 27 siswa $(67,5 \%)$, sedangkan kategori baik sebanyak 13 siswa $(32,5 \%)$.

4. Dari hasil uji Chi-square terdapat hubungan bermakna antara konsumsi makanan kariogenik dengan kejadian karies gigi $\mathrm{p}$ value $=0.004$ ( $\mathrm{p}$ value $=<0,05)$. Sehingga $\mathrm{Ha}$ diterima yang artinya terdapat hubungan antara konsumsi makanan kariogenik dengan kejadian karies gigi pada anak sindrom di SLB Dharma Bakti Dharma Pertiwi Bandar Lampung.

5. Dari hasil uji Chi-square terdapat hubungan bermakna antara peran orang tua dalam kebiasaan menggosok gigi dengan kejadian karies gigi $p$ value $=0.000$ ( $p$ value $=<0,05)$. Sehingga $\mathrm{Ha}$ diterima yang artinya terdapat hubungan antara konsumsi makanan kariogenik dengan kejadian karies gigi pada anak sindrom di SLB Dharma Bakti Dharma Pertiwi Bandar Lampung.

\section{SARAN}

Beberapa saran terkait yang dapat peneliti berikan berkaitan dengan hubungan konsumsi makanan kariogenik dan kebiasaan menggosok 
gigi dengan kejadian karies gigi pada anak sindrom down di SLB Dharma Bakti Dharma Pertiwi Bandar Lampung.

1. Bagi subyek

a. Anak sindrom down di SLB Dharma Bakti Dharma Pertiwi Bandar Lampung

Disarankan bagi para murid untuk mengurangi kebiasaan makan makanan manis seperti permen, cokelat, dan gulali agar menurunkan faktor resiko terjadinya karies gigi, menjaga kebersihan mulut seperti menyikat gigi dan berkumurkumur setelah memakan makanan manis, dan pengontrolan karies yang rutin ke dokter gigi.

b. Orang tua/wali anak sindrom down di SLB Dharma Bakti Dharma Pertiwi Bandar Lampung Diharapkan kepada orang tua untuk memberikan perhatian khusus dan mengajarkan anak atau menemani anak untuk membiasakan menggosok gigi setelah sarapan dan sebelum tidur malam. Karna dalam hal pemeliharaan gigi mulut anak sindrom down sangat bergantung pada orang tuanya.

2. Bagi institusi

a. Universitas Malahayati Bandar Lampung

Diharapkan dapat menambah daftar pustaka, menambah wawasan dan pengetahuan untuk mahasiswa/mahasiswi yang membaca.

b. Dinas Pendidikan Bandar Lampung

Perlu diadakan edukasi terhadap setiap sekolah untuk lebih meningkatkan status kesehatan mulut dan gigi dan memotivasi terhadap guru-guru untuk membiasakan hidup sehat kepada siswa/siswi.

c. Sekolah Luar Biasa (SLB) Dharma Bakti Dharma Pertiwi Bandar Lampung

Diharapkan bagi sekolah agar lebih meningkatakan status kesehatan gigi, menerangkan kepada murid mengenai makanan yang baik untuk gigi, yaitu makanan yang berpotensi rendah menyebabkan karies dan makanan yang menghambat karies, dan memotivasi anak untuk membiasakan menggosok gigi setelah sarapan pagi dan sebelum tidur malam.

d. Dinas Kesehatan Bandar Lampung

Diperlukan adanya pemeriksaan gigi yang rutin terhadap anak sindrom down, dilakukan penyuluhan dan kunjungan rutin untuk kesehatan gigi dan mulut khususnya bagi petugas puskesmas Beringin Raya. Supaya perilaku kesehatan gigi anak yang baik dapat dibentuk sejak dini terutama untuk anak sindrom down di SLB Dharma Bakti Dharma Pertiwi Bandar Lampung.

Perlu dilakukan edukasi terhadap orang tua/wali anak sindrom down di Sekolah Luar Biasa (SLB) Dharma Bakti Dharma Pertiwi Bandar Lampung mengenai dampak kebiasaan buruk yang mempengaruhi kesehatan rongga mulut misalnya konsumsi makanan kariogenik dan kebiasaan menggosok gigi yang tidak baik.

3. Bagi peneliti selanjutnya

Diharapkan ada peneliti selanjutnya mengenai faktor-faktor yang berhubungan dengan prevalensi karies gigi pada anak, untuk memperdalam pengetahuan tentang faktor-faktor yang sudah ada ataupun menemukan faktorfaktor lainnya.

\section{DAFTAR PUSTAKA}

Gopdianto, R., Rattu, A. M., \& Mariati, N. W. (2014). Status kebersihan mulut dan perilaku menyikat gigi anak SD Negeri 1 Malalayang. e-GIGI, 3(1). 
Imai, P. H., \& Hatzimanolakis, P. C. (2010). Encouraging client compliance for interdental care with the interdental brush: the client's perspective. Canadian Journal of Dental Hygiene, 44(2).

Irdawati, I., \& Muhlisin, A. (2017). Sindrom Down Pada Anak Ditinjau dari Segi Biomedik dan

Penatalaksanaannya. Berita IImu Keperawatan. Vol 2(1), 47-50.

Irma, I., \& Intan, A. (2013). Penyakit Gigi, Mulut dan THT. Oral Hygiene. Yogyakarta: Nuha Medika.

Janet Jaccarino, C. D. A., \& DH, M. (2009). Treating the special needs patient with a developmental disability: cerebral palsy, autism and Down syndrome. Dental Assistant. Vol. 78(6), hal. 7.

Kandani, H. (2010). The achiever. Elex Media Komputindo.

Kesehatan, K. (2013). Riset Kesehatan Dasar (Riskesdas). Kemenkes RI.

Khairani, K., Busman, B., \& Edrizal, E. (2017). Uji Aktivitas Antibakteri Ekstrak Jamur Tiram Putih (Pleurotus Ostreatus) Terhadap Bakteri Streptococcus Mutans Penyebab Karies Gigi. BDent: Jurnal Kedokteran Gigi Universitas Baiturrahmah. Vol. 4(2), hal. 110-116.

Marya, C. M. (2011). A textbook of public health dentistry. JP Medical Ltd.

Maryamatussalamah, H. (2013). Kegiatan Bernyanyi Pada Siswa Down Syndrome Di SLB-C Yayasan Karya Bakti Garut. SWARA. Vol. 1(3).

Ningrum, R. P. (2014). Kebiasaan Konsumsi Air Hujan Terhadap Status Keparahan Karies Gigi Pada Masyarakat Di Desa Aji Kuning Kecamatan Sebatik Tengah Kabupaten Nunukan Tahun 2014.
Ningsih, D. M. D. A., Hutomo, L. C., \& Rahaswanti, L. W. A. (2013). Gambaran Perilaku Menggosok Gigi terhadap Kejadian Karies Gigi pada Anak Usia Sekolah Dasar di Wilayah Kerja Puskesmas Sidemen, Kecamatan Sidemen, Kabupaten Karangasem, pada Juni-Juli 2013. E-Jurnal Medika Udayana.

Notoatmojo, S. (2010). Metodelogi Penelitian Survei. Jakarta: Rineka Cipta. 37-38.

Nurfalah, A., Yuniarrahmah, E., \& Aspriyanto, D. (2014). Efektivitas Metode Peragaan Dan Metode Video Terhadap Pengetahuan Penyikatan Gigi Pada Anak Usia 9-12 Tahun Di SDN Keraton 7 Martapura. Jurnal Kedokteran Gigi. 144.

Pathak, A. K., Shakya, V. K., Chandra, A., \& Goel, K. (2013). Association between diabetes mellitus and periodontal status in north Indian adults. European Journal of General Dentistry. Vol. 2(1), hal. 58.

Profil Kesehatan Provinsi Lampung Tahun 2013. Bandar Lampung.

Ramadhan, A. G. (2010). Serba serbi kesehatan gigi dan mulut. Jakarta: Bukune. Hal. 186.

Roberson, T., Heymann, H. O., \& Swift Jr, E. J. (2013). ARABIC-Sturdevant's art and science of operative dentistry: Arabic bilingual edition. Elsevier Health Sciences.

Situmorang, C. (2011). Hubungan Sindroma Down dengan Umur Ibu, Pendidikan Ibu, Pendapatan Keluarga, dan Faktor Lingkungan. Jurnal Kedokteran Indonesia, Vol. 2(1), 96-101. 
Soetjiningsih (2016). Tumbuh

Kembang Anak. Jakarta :

EGC; 1995. Hal. 211

Sumini, S., Amikasari, B., \& Nurhayati, D. (2014). Hubungan konsumsi makanan manis dengan kejadian karies gigi pada anak prasekolah di TK B RA Muslimat PSM Tegalrejodesa Semen Kecamatan Nguntoronadi Kabupaten Magetan. Jurnal Delima Harapan. vol. 1(1), hal. 20-27. 